\title{
Model of a nonlinear reaction system with autocatalysis and autoinhibition: Stability of dynamic states
}

\author{
Stevan Maćešić ${ }^{1}$, Željko Čupić $^{2}$, Ljiljana Kolar-Anić ${ }^{1}$ \\ ${ }^{1}$ University of Belgrade, Faculty of Physical Chemistry, Belgrade, Serbia \\ ${ }^{2}$ University of Belgrade, Institute of Chemistry, Technology and Metallurgy, Department of Catalysis and Chemical \\ Engineering, Belgrade, Serbia
}

\begin{abstract}
Self-regulation, achieved through positive (autocatalytic) or negative (autoinhibitory) feedback is commonly encountered in natural, technological and economic systems. The dynamic behavior of such systems is often complex and cannot be easily predicted, necessitating mathematical modelling and theoretical analyses. The aim of this work is to analyze the dynamics of a minimal model system with autocatalytic and autoinhibitory steps coupled through the same species, in order to understand under which critical condition the system loses stability and passes through an Andronov-Hopf bifurcation. The analysis used was improved stoichiometric network analysis (SNA) in combination with bifurcation and sensitivity analysis.
\end{abstract}

SCIENTIFIC PAPER

UDC 544.474:544:517.9

Hem. Ind. 66 (5) 637-646 (2012)

doi: 10.2298/HEMIND120210034M

Keywords: Nonlinear dynamics; stoichiometric network analysis; autocatalysis; HPA system; Andronov-Hopf bifurcation.

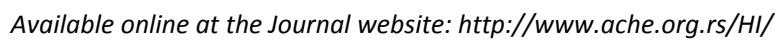

Autocatalysis and autoinhibition often exist together in complex dynamical systems that exhibit selfregulation, but the feedback is not necessarily achieved through the same intermediate species. We analyze here a low-dimensional reaction model where positive and negative feedback loops are coupled, occurring through the same species. In order to understand how the stability of this system is affected by the concentrations of other reactive species and the kinetic rate constants, we have generated MATLAB routines for improved stoichiometric network analysis (SNA) [1]. We use stability and bifurcation analyses for a detailed discussion of dynamic states.

\section{THE MODEL}

The Model $\left(R_{1}\right)-\left(R_{9}\right)$ (Table 1$)$, consists of four reaction species ( $B, M, A$ and $G$ ) and nine reactions characterized by kinetic rate constants $k_{i}(i=1,2, \ldots, 9)$.

It contains one positive (R6) and one negative (R7) feedback loop that are coupled through the same intermediate $(\mathrm{G})$. These two reactions are important for oscillatory behavior of the systems $[2,3]$.

Positive/negative feedback coupling can be found in many natural systems, such as the hypothalamo-hypofizo adrenal (HPA) axis [4].

The dynamics of the Model $\left(R_{1}\right)-\left(R_{9}\right)$ can be represented by a set of ordinary differential kinetic equations:

Correspondence: S. Maćešić, University of Belgrade, Faculty of Physical Chemistry, Studentski trg 12-16, 11000 Belgrade, Serbia.

E-mail: macesic.stevan@gmail.com

Paper received: 10 February, 2012

Paper accepted: 20 March, 2012

$$
\begin{aligned}
& \frac{\mathrm{d} b}{\mathrm{~d} t}=k_{1}-k_{3} b \\
& \frac{\mathrm{d} m}{\mathrm{~d} t}=k_{2}+k_{5} a-k_{7} m g^{2} \\
& \frac{\mathrm{d} a}{\mathrm{~d} t}=k_{3} b-k_{4} a-k_{5} a-k_{6} a g^{2}-k_{8} a \\
& \frac{\mathrm{d} g}{\mathrm{~d} t}=k_{4} a+k_{6} a g^{2}-k_{7} m g^{2}-k_{9} g
\end{aligned}
$$

where $a, b, g$, and $m$ are concentrations of intermediate reaction species $A, B, G$ and $M$, respectively; $t$ is the time. Having four variables, this model cannot be analyzed by standard mathematical procedure appropriate for two or three variables, requiring improved stoichiometric network analysis [5].

Table 1. Model $\left(R_{1}\right)-\left(R_{g}\right)$ which consists nine reactions $\left[\left(R_{1}\right)-\left(R_{g}\right)\right]$

\begin{tabular}{lcccc}
\hline & \multicolumn{2}{c}{ Reaction } & Rate constant & \\
\hline & $\stackrel{k_{1}}{\longrightarrow}$ & $\mathrm{B}$ & $k_{1}=1.83 \times 10^{-8} \mathrm{~min}^{-1}$ & $\left(\mathrm{R}_{1}\right)$ \\
& $\stackrel{k_{2}}{\longrightarrow} \mathrm{M}$ & $\mathrm{k}_{2}=6.09 \times 10^{-11} \mathrm{~min}^{-1}$ & $\left(\mathrm{R}_{2}\right)$ \\
$\mathrm{B}$ & $\stackrel{k_{3}}{\longrightarrow}$ & $\mathrm{A}$ & $k_{3}=1.83 \mathrm{~min}^{-1}$ & $\left(\mathrm{R}_{3}\right)$ \\
$\mathrm{A}$ & $\stackrel{k_{4}}{\longrightarrow}$ & $\mathrm{G}$ & $k_{4}=3.60 \times 10^{-2} \mathrm{~min}^{-1}$ & $\left(\mathrm{R}_{4}\right)$ \\
$\mathrm{A}$ & $\stackrel{k_{5}}{\longrightarrow}$ & $\mathrm{M}$ & $k_{5}=2.88 \times 10^{-4} \mathrm{~min}^{-1}$ & $\left(\mathrm{R}_{5}\right)$ \\
$\mathrm{A}+2 \mathrm{G}$ & $\stackrel{k_{6}}{\longrightarrow}$ & $3 \mathrm{G}$ & $k_{6}=1.26 \times 10^{14} \mathrm{~min}^{-1} \mathrm{~mol}^{-2} \mathrm{dm}^{6}$ & $\left(\mathrm{R}_{6}\right)$ \\
$\mathrm{M}+2 \mathrm{G}$ & $\stackrel{k_{7}}{\longrightarrow}$ & $\mathrm{G}$ & $k_{7}=7.05 \times 10^{12} \mathrm{~min}^{-1} \mathrm{~mol}^{-2} \mathrm{dm}^{6}$ & $\left(\mathrm{R}_{7}\right)$ \\
$\mathrm{A}$ & $\stackrel{k_{8}}{\longrightarrow}$ & $\mathrm{P}_{1}$ & $k_{8}=5.35 \times 10^{-2} \mathrm{~min}^{-1}$ & $\left(\mathrm{R}_{8}\right)$ \\
$\mathrm{G}$ & $\stackrel{k_{9}}{\longrightarrow}$ & $\mathrm{P}_{2}$ & $k_{9}=4.10 \times 10^{-1} \mathrm{~min}^{-1}$ & $\left(\mathrm{R}_{9}\right)$ \\
\hline
\end{tabular}




\section{Stoichiometric network analysis of considered model}

In SNA [5-7], the kinetic equations of any stoichiometric model presented by a set of differential kinetic equations such as (1) are written in the matrix form:

$$
\dot{\mathbf{c}}=\mathbf{S} \times \mathbf{v}
$$

where $\dot{\mathbf{c}}$ is the time derivative of the $m \times 1$ concentration vector $c$ comprising the change in concentrations of $m$ independent intermediate species, known as internal ones in SNA. $\mathbf{S}$ is the stoichiometric matrix and $\mathbf{v}$ is the so-called reaction or flux vector with reaction rates as components. The stoichiometric matrix $\mathbf{S}$ is an $m \times n$ matrix where $n$ is the number of reactions in the reaction network (in the model considered $m=4$ and $n=9$ ). The $S_{i k}$ element of the stoichiometric matrix corresponds to the stoichiometric coefficient of reactive species $i$ in reaction $\left(R_{k}\right)$ corresponding to column $k$ and row $i$. The reaction vector $\mathbf{v}$ is a $1 \times n$ vector whose elements describe the reaction rates.

Using the matrix representation given in Eq. (2), the Model $\left(R_{1}\right)-\left(R_{9}\right)$ (Table 1$)$ corresponds to the following system of differential equations:

$$
C=\left[\begin{array}{ccccccccc}
R_{1} & R_{2} & R_{3} & R_{4} & R_{5} & R_{6} & R_{7} & R_{8} & R_{9} \\
1 & 0 & -1 & 0 & 0 & 0 & 0 & 0 & 0 \\
0 & 1 & 0 & 0 & 1 & 0 & -1 & 0 & 0 \\
0 & 0 & 1 & -1 & -1 & -1 & 0 & -1 & 0 \\
0 & 0 & 0 & 1 & 0 & 1 & -1 & 0 & -1
\end{array}\right] \times\left[\begin{array}{c}
v_{1} \\
v_{2} \\
v_{3} \\
v_{4} \\
v_{5} \\
v_{6} \\
v_{7} \\
v_{8} \\
v_{9}
\end{array}\right]
$$

Now, we want to obtain information about the interplay between the concentrations of independent intermediate species and the dynamics of the network as a whole. As a first step, we look for conditions where the network is in a quasi steady state. The rates at a steady state $v_{\mathrm{ss}}$ are solutions of the relation [4]:

$$
0=\mathbf{S} \times v_{\mathrm{ss}}
$$

Equation (4) represents a system of homogenous equations, and we need to find all its positive solutions. The method of finding all positive solutions of Eq. (4) depends on the size of the examined model. For simpler models, Eq. (4) can be solved by hand. However, if the number of reactions is large, solving Eq. (4) becomes much more complex and the only suitable way is to use computer programs based on algorithms developed for this purpose [8-12].

The solutions of Eq. (4), known as extreme currents $[5,6]$, are reaction pathways in steady state. They offer important information about the consistency of the model, and correlations between individual reactions like mutual exclusion or coupling [13]. The extreme currents $E_{i}$ are usually presented as the columns (in any order) of a new extreme current matrix $\mathbf{E}$. In the case considered, it is:

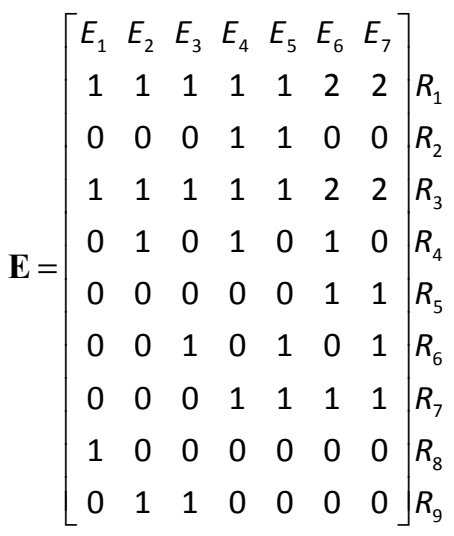

In any specific steady state, each extreme current contributes to reaction rates with its own, distinct, extent. The contributions of the extreme currents, denoted as the current rates $j_{i}$, are given as the components of the corresponding vector $\mathbf{j}$. Elements of vector $\mathbf{j}$ are nonnegative numbers. The basic equation of the SNA gives relation between rates at a steady state $v_{s s, k}$ and current rates $j_{k}[4]$ :

$v_{\mathrm{ss}}=\mathbf{E j}$

Using Eq. (6), the particular reaction step rate $v_{\mathrm{ss}, k}$ can be written in the form:

$v_{\mathrm{ss}, 1}=j_{1}+j_{2}+j_{3}+j_{4}+j_{5}+2 j_{6}+2 j_{7}$

$v_{\mathrm{ss}, 2}=j_{4}+j_{5}$

$v_{\mathrm{ss}, 3}=j_{1}+j_{2}+j_{3}+j_{4}+j_{5}+2 j_{6}+2 j_{7}$

$v_{\mathrm{ss}, 4}=j_{2}+j_{4}+j_{6}$

$v_{\mathrm{ss}, 5}=j_{6}+j_{7}$

$v_{\mathrm{ss}, 6}=j_{3}+j_{5}+j_{7}$

$v_{\mathrm{ss}, 7}=j_{4}+j_{5}+j_{6}+j_{7}$

$v_{\mathrm{ss}, 8}=j_{1}$

$v_{\mathrm{ss}, 9}=j_{2}+j_{3}$

The next step in our analysis is to examine the stability of a steady state, to find the instability condition. The stability analysis of the particular steady states is usually performed on the linearized form of the general equation of motion of a system around the steady state. Namely, when the system is in a steady state little perturbation of the concentrations of intermediate species can be given as linear deviation from the steady state concentrations [14]:

$c=c_{\mathrm{ss}}+\Delta c$ 
We can expand the time derivative of concentration vector $c$ in a Taylor series near a steady state $c_{s s}$ and keep the leading terms only (see Appendix III):

$$
\frac{\mathrm{d} c}{\mathrm{~d} t}=\frac{\mathrm{d}\left(c_{\mathrm{ss}}+\Delta c\right)}{\mathrm{d} t}=\frac{\mathrm{d} \Delta c}{\mathrm{~d} t}=\mathbf{M} \Delta c
$$

The leading term $\mathbf{M}$ is a Jacobian matrix, which in SNA has the form:

$$
\mathbf{M}\left(h, v_{\text {ss }}\right)=\operatorname{Sdiag}\left(v_{\text {ss }}\right) \mathbf{K}^{T} \operatorname{diag}(h)
$$

where $\operatorname{diag}(h)$ is a diagonal matrix whose elements $h_{i}$ are the reciprocal of the steady state concentrations of the species $i$, for $i=1, \ldots, 4$, and $\mathbf{K}$ is the matrix of the order of reactions with its transpose $\mathbf{K}^{T}$. Hence, the stability is defined by the sign of the real part of the eigenvalues of the Jacobian matrix. A general derivation of the Jacobian matrix $\mathbf{M}$ is given in references [7] and [14]. For the model under consideration, the matrix $\mathbf{K}$ is:

$$
\mathbf{K}=\left[\begin{array}{ccccccccc}
R_{1} & R_{2} & R_{3} & R_{4} & R_{5} & R_{6} & R_{7} & R_{8} & R_{9} \\
0 & 0 & 1 & 0 & 0 & 0 & 0 & 0 & 0 \\
0 & 0 & 0 & 0 & 0 & 0 & 1 & 0 & 0 \\
0 & 0 & 0 & 1 & 1 & 1 & 0 & 1 & 0 \\
0 & 0 & 0 & 0 & 0 & 2 & 2 & 0 & 1
\end{array}\right] \begin{gathered}
B \\
G \\
G
\end{gathered}
$$

According to Eq. (6), Eq (10) can be transformed to the matrix equation:

$$
\mathbf{M}(h, j)=S \operatorname{diag}(\mathbf{E} j) \mathbf{K}^{T} \operatorname{diag}(h)
$$

The matrix $\mathbf{M}$ written as a function of the SNA parameters $j_{i}$ and $h_{i}$ has particular advantages for the stability analysis since these parameters are non-negative, which is an essential feature of the SNA. The steady-state stability is determined by the sign of eigenvalues of $\mathbf{M}$, which are the roots $\lambda$ of the characteristic polynomial [15]:

$$
|\lambda \mathbf{I}-\mathbf{M}|=\sum_{i=0}^{n} \alpha_{i} \lambda^{n-i}
$$

where, for the considered model, $n=4$. If the real parts of all eigenvalues are negative, a steady state is stable. If one or more eigenvalues has positive real parts the steady state is unstable. The number of eigenvalues with positive real parts can be determined by the Routh-Hurwitz criterion. According to this criterion, the number of eigenvalues with positive real parts is equal to the number of the sign changes in the Routh array [15]:

$$
R=\left(1, \Delta_{1}, \frac{\Delta_{2}}{\Delta_{1}}, \frac{\Delta_{3}}{\Delta_{2}}, \ldots, \frac{\Delta_{n}}{\Delta_{n-1}}\right)
$$

where $\Delta_{i}, i=1, \ldots, n$, is $i$-th Hurwitz determinant, defined as the determinant of the leading principal minor of the Hurwitz matrix $\mathbf{H}$, where leading principal minor of dimension $i$ is matrix constructed from the first $i$ rows and columns of matrix $\mathbf{H}$ :

$$
\mathbf{H}=\left[\begin{array}{cccccc}
\alpha_{1} & \alpha_{3} & \alpha_{5} & \alpha_{7} & \ldots & \alpha_{2 n-1} \\
1 & \alpha_{2} & \alpha_{4} & \alpha_{6} & \ldots & \alpha_{2 n-2} \\
0 & \alpha_{1} & \alpha_{3} & \alpha_{5} & \ldots & \alpha_{2 n-3} \\
0 & 1 & \alpha_{2} & \alpha_{4} & \ldots & \alpha_{2 n-4} \\
0 & 0 & \alpha_{1} & \alpha_{3} & \ldots & \alpha_{2 n-5} \\
\vdots & \vdots & \vdots & \vdots & \ddots & \vdots \\
0 & 0 & 0 & 0 & \ldots & \alpha_{n}
\end{array}\right]
$$

Obviously, $\alpha_{i}=0$ for $i>n$. The steady state is stable if all Hurwitz determinants are positive. If there is only one sign change in the Routh array (14), this indicates that only one eigenvalue has positive real part. Such instability occurs when the largest Hurwitz determinant changes its sign keeping all others positive, and this point presents saddle-node bifurcation. From the Hurwitz matrix (15) we can see that the largest Hurwitz determinant $\Delta_{n}$ can be written as:

$\Delta_{n}=\alpha_{n} \times \Delta_{n-1}$

Since the sign of the largest Hurwitz determinant is in this case determined by the sign of the largest coefficient of the characteristic polynomial $\alpha_{n}$, the saddle-node bifurcation can be identified from [15]:

$\alpha_{n}=0$

The Hurwitz matrix gives us also the condition for appearance of the Andronow-Hopf bifurcation, which is of great importance because it is the source of oscillations in the system. The Andronow-Hopf bifurcation is a local bifurcation in which the dynamical system loses stability as a pair of two complex conjugate eigenvalues cross the imaginary axis. This bifurcation indicates an appearance or disappearance of periodic behavior. The Andronow-Hopf bifurcation occurs when $[15,16]$ :

$\Delta_{n-1}=0$

For considered model where $n=4$, the Hurwitz matrix is:

$\mathbf{H}=\left[\begin{array}{cccc}\alpha_{1} & \alpha_{3} & 0 & 0 \\ 1 & \alpha_{2} & \alpha_{4} & 0 \\ 0 & \alpha_{1} & \alpha_{3} & 0 \\ 0 & 1 & \alpha_{2} & \alpha_{4}\end{array}\right]$

and the condition for appearance of Andronow-Hopf bifurcation given in Eq. (18) is: 


$$
\Delta_{3}=\left[\begin{array}{ccc}
\alpha_{1} & \alpha_{3} & 0 \\
1 & \alpha_{2} & \alpha_{4} \\
0 & \alpha_{1} & \alpha_{3}
\end{array}\right]=\alpha_{1} \alpha_{2} \alpha_{3}-\alpha_{3}^{2}-\alpha_{4} \alpha_{1}^{2}=0
$$

Application of an instability condition obtained by this method becomes limited by the number of independent internal species and it is often very difficult to be determined by the classical procedure, but this method is convenient for a numerical evaluation of stability of steady state. A much simpler method to examine the steady-state stability is the use of the matrix of current rates $\mathbf{V}(j)$, where:

$$
\mathbf{V}(j)=-\mathbf{S} \operatorname{diag}(\mathbf{E} j) \mathbf{K}^{T}
$$

The steady state is considered to be unstable if there is at least one negative diagonal minor of $\mathbf{V}(j)$. [6] Although it is an approximation, this criterion often gives satisfactory results. The matrix $\mathbf{V}(j)$ for the model considered is:

$$
\mathbf{V}(j)=\left[\begin{array}{cccc}
j_{1}+j_{2}+j_{3}+j_{4}+j_{5}+2 j_{6}+2 j_{7} & 0 & 0 & 0 \\
0 & j_{4}+j_{5}+j_{6}+j_{7} & -\left(j_{6}+j_{7}\right) & 2\left(j_{4}+j_{5}+j_{6}+j_{7}\right) \\
-\left(j_{1}+j_{2}+j_{3}+j_{4}+j_{5}+2 j_{6}+2 j_{7}\right) & 0 & j_{1}+j_{2}+j_{3}+j_{4}+j_{5}+2 j_{6}+2 j_{7} & 2\left(j_{3}+j_{5}+j_{7}\right) \\
0 & j_{4}+j_{5}+j_{6}+j_{7} & -\left(j_{2}+j_{3}+j_{4}+j_{5}+j_{6}+j_{7}\right) & j_{2}-j_{3}+2 j_{4}+2 j_{6}
\end{array}\right]
$$

We examined all diagonal minors and detected those with negative terms, since only these minors can be negative. They are negative when the polynomial obtained from the corresponding determinant is negative. The calculated polynomials have to be compared between one another, the core of instability must be recognized, and the essential one ought to be selected. The aim is to find the polynomial with less possible order. Such obtained polynomials are expressed as a function of $j_{i}$. In the case considered the selected polynomial is:

However, working with parameters $j_{i}$ is not practical, because they do not have unique solutions, so a much better way is to transform them into rate velocities. [1] Linear relations between $j_{i}$ and $v_{s s, i}$ can be found from matrix E and Eq. (6), and they are given in Eq. (7). After the transformation, the condition that is critical for the existence of periodic behavior is:

$v_{\mathrm{ss}, 2}+v_{\mathrm{ss}, 4}+v_{\mathrm{ss}, 5}<v_{\mathrm{ss}, 6}$

Equation (24) gives the critical condition, which needs to be fulfilled for periodic temporal evolution of intermediate species that are involved in dynamics of HPA system model, for rate constants given in Table 1.

To determine which diagonal minors with negative terms are the most important for the existence of periodic behavior, it is necessary to perform comparative

$$
j_{2}-j_{3}+2 j_{4}+2 j_{6}<0
$$

analysis with experiments and the numerical simulations. These analyses allow us to determine which terms in the polynomial obtained from corresponding determinant are dominant.

\section{Numerical analysis of considered model}

Using SNA we can obtain very important information about the steady-state stability, interaction between reaction species in a steady state, and possible reaction routes. However, this method does not give detailed information about the dynamics of the system, such as type of the oscillations together with their amplitudes and periods. To obtain such informerical and sensitivity analyses, and numerical integration of a system of ordinary differential equations. However, we had to adapt them in such a manner that they can use main results of SNA. For this purpose we developed corresponding computer programs in Matlab mation it is necessary to use additional methods of nu-

and applied them on the model given in Table 1. These adopted methods allowed us to examine how the oscillatory dynamics of the system responds to changes of rate constants given in Table 1.

As a first step in numerical analysis of the model, we numerically solved system of ordinary differential equations with rate constants given in Table 1 that satisfies the instability condition (24). The results are given in Figure 1. Oscillatory behavior can be seen, involving intermediate species $A, M$ and $G$, while intermediate species $B$ has only non-oscillatory evolution.

Now we were interested to determine the importance of each reaction in the model to the stability of the system. Although only several reactions are involved in condition given in equation (24), we cannot exclude other reactions from model without determining their effect on periodic behavior of the system. To do that, we had to use sensitivity analysis. We varied rate constants in certain range of values and tested for existence of Andronow-Hopf bifurcation by calculating $\Delta_{3}$. Details of this analysis can be found in Appendix I, while the most important results are given in Table 2.

What we have found is that autocatalysis is the dominant process, which is essential for the existence of oscillations in the model, and excluding autocatalysis from the model cancels all negative terms in all diagonal minors of matrix $\mathbf{V}(j)$, making the system stable. Autoinhibition $\left(R_{7}\right)$ on the other hand does not affect 
a)

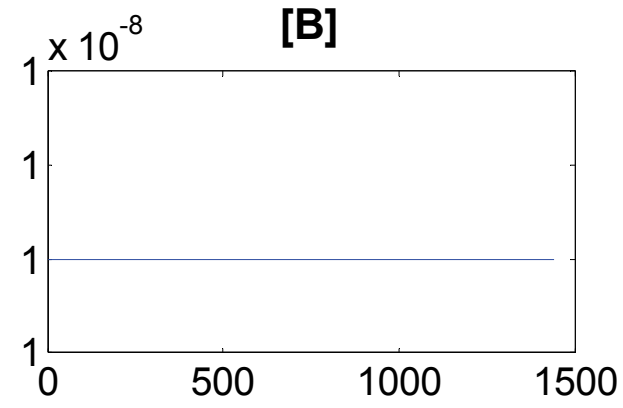

c)

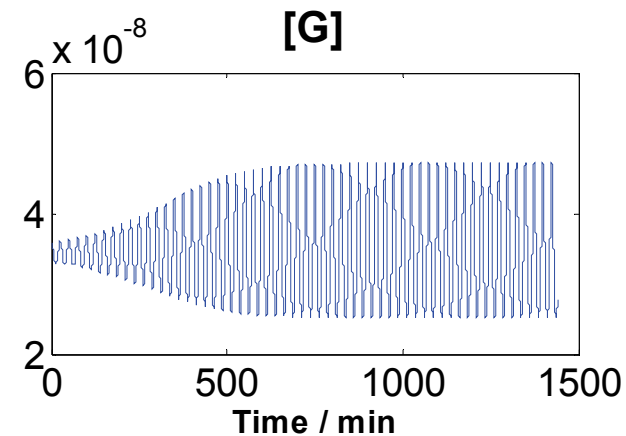

b)
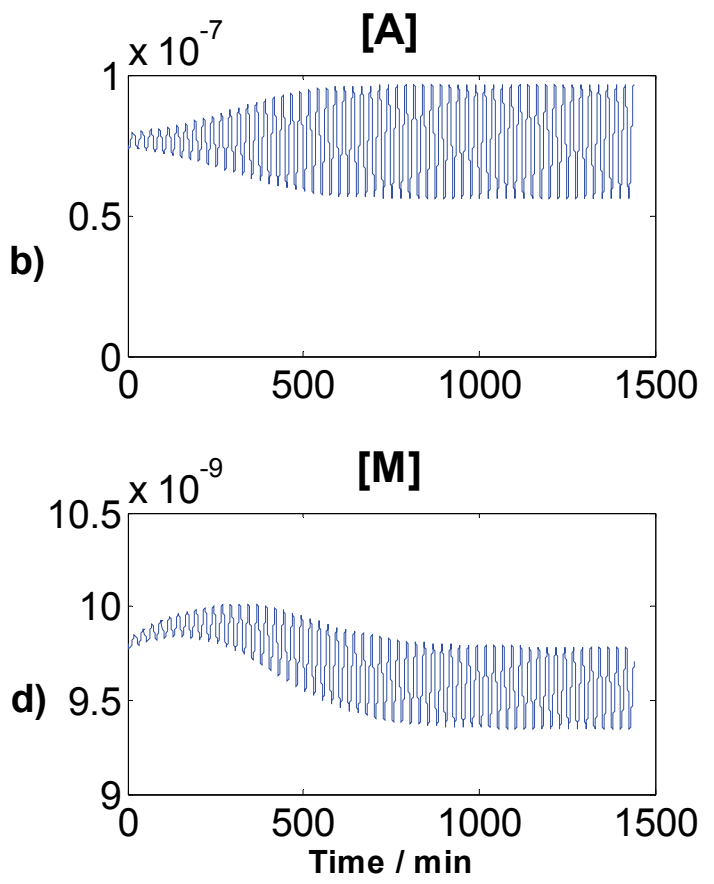

Figure 1. Temporal concentration evolution of the species $B, A$, G and $M$ in the model given in Table 1 obtained by numerically solving system of ordinary differential equations (Eq.(1)) for the intermediates species a) $B, b) M, c) A$ and d) $G$. The concentration of the species is given in $\mathrm{mol} \mathrm{dm}^{-3}$.

stability of the system in general, but this process is necessary for intermediate species $M$ to oscillate. We determined that the rate constants of reactions $\left(R_{2}\right)$, $\left(R_{5}\right),\left(R_{7}\right)$ and $\left(R_{8}\right)$ did not have lower limits and removing all of them from the model did not affect system stability. All these reactions, except $\left(R_{8}\right)$, are reactions that control dynamics of the intermediate species $M$, and do not interfere in dynamics of other species in system. Although autoinhibition, which is represented by reaction $\left(R_{7}\right)$, introduce nonlinear terms in model, these terms did not have a destabilizing effect in our case. Periodic behavior of species $M$ occurs as a result of coupling with intermediate species $G$, which participate in autocatalysis.

Table 2. Range of values of rate constants where exists Andronow-Hopf bifurcation

\begin{tabular}{lcc}
\hline \multirow{2}{*}{ constant } & \multicolumn{2}{c}{ Range } \\
\cline { 2 - 3 } & Minimum value & Maximum value \\
\hline$k_{1}$ & $1.6 \times 10^{-8} \mathrm{~min}^{-1}$ & $2.0 \times 10^{-8} \mathrm{~min}^{-1}$ \\
$k_{2}$ & 0 & $7.7 \times 10^{-10} \mathrm{~min}^{-1}$ \\
$k_{3}$ & $1.0 \times 10^{-3} \mathrm{~min}^{-1}$ & Inf \\
$k_{4}$ & $4.0 \times 10^{-3} \mathrm{~min}^{-1}$ & $4.0 \times 10^{-2} \mathrm{~min}^{-1}$ \\
$k_{5}$ & 0 & $5.0 \times 10^{-3} \mathrm{~min}^{-1}$ \\
$k_{6}$ & $9.7 \times 10^{13} \mathrm{~min}^{-1}$ & $1.42 \times 10^{14} \mathrm{~min}^{-1}$ \\
& $\mathrm{~mol}^{-2} \mathrm{dm}^{6}$ & $\mathrm{~mol} \mathrm{dm}^{6}$ \\
$k_{7}$ & 0 & $\mathrm{Inf}^{-2}$ \\
$k_{8}$ & 0 & $0.65 \times 10^{-2} \mathrm{~min}^{-1}$ \\
$k_{9}$ & $0.3994 \mathrm{~min}^{-1}$ & $0.5112 \mathrm{~min}^{-1}$ \\
\hline
\end{tabular}

The model is greatly simplified by removing reactions $\left(R_{2}\right),\left(R_{5}\right),\left(R_{7}\right)$ and $\left(R_{8}\right)$ from it and leaving only reactions that are core of instability responsible for periodic behavior (Table 3 ). Results of numerical simulation of simplified model, very similar to the model known as autocatalator [17] are given in Figure 2.

Table 3. Simplified model developed from the model $\left(R_{1}\right)-\left(R_{9}\right)$

\begin{tabular}{|c|c|c|c|}
\hline Reaction & & Rate constant & \\
\hline$\stackrel{k_{1}}{\longrightarrow}$ & B & $k_{1}=1.83 \times 10^{-8} \mathrm{~min}^{-1}$ & $\left(R_{1}\right)$ \\
\hline $\mathrm{B} \stackrel{k_{3}}{\longrightarrow}$ & A & $k_{3}=1.83 \mathrm{~min}^{-1}$ & $\left(R_{3}\right)$ \\
\hline $\mathrm{A} \stackrel{k_{4}}{\longrightarrow}$ & G & $k_{4}=3.60 \times 10^{-2} \mathrm{~min}^{-1}$ & $\left(R_{4}\right)$ \\
\hline$A+2 G \stackrel{k_{6}}{\longrightarrow}$ & $3 G$ & $k_{6}=1.26 \times 10^{14} \mathrm{~min}^{-1} \mathrm{~mol}^{-2} \mathrm{dm}^{6}$ & $\left(R_{6}\right)$ \\
\hline $\mathrm{G} \stackrel{k_{9}}{\longrightarrow}$ & $\mathrm{P}_{2}$ & $k_{9}=0.410 \mathrm{~min}^{-1}$ & $\left(R_{g}\right)$ \\
\hline
\end{tabular}

\section{Stoichiometric network analysis of simplified model}

With the aim to examine the dynamics of the simplified model, we performed SNA on it and as a first step we calculated matrix E. New matrix E (Eq. (25)) is reduced to two columns of previous matrix $\mathbf{E}$. All columns that contain removed reactions are cancelled. Both of the remaining extreme currents are essential for the periodic behaviour: 
a)

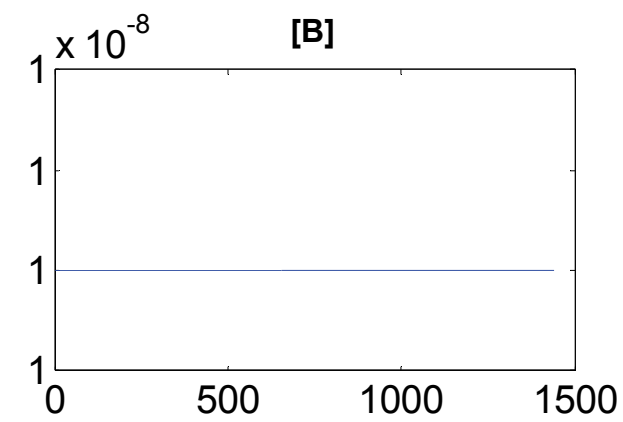

c)

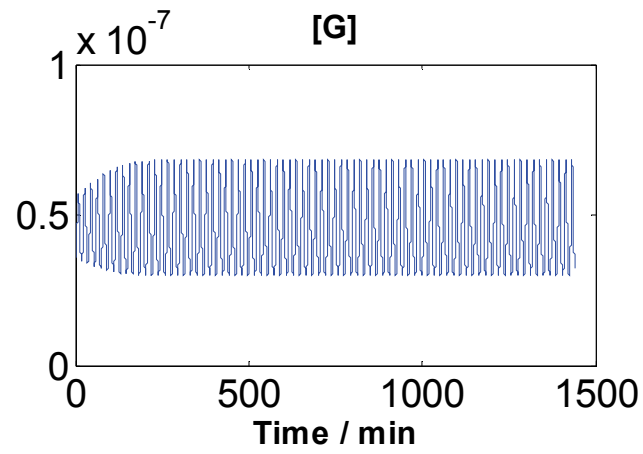

b)

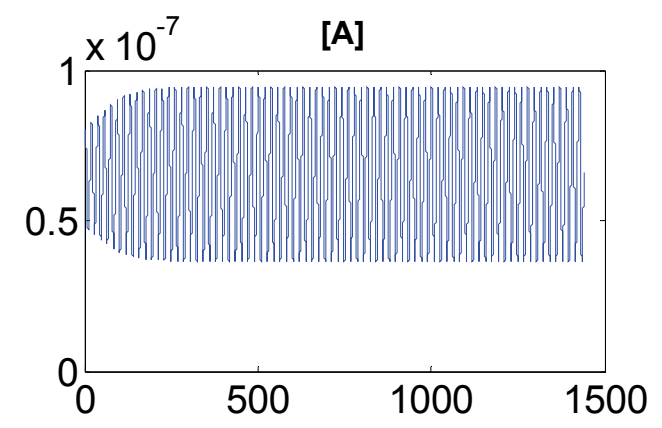

d)

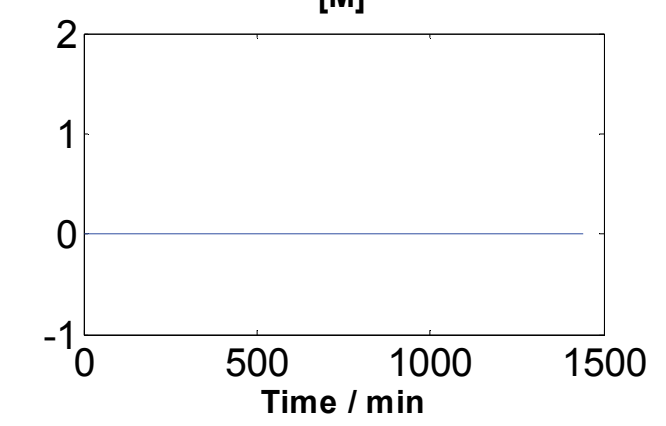

Figure 2. Temporal concentration evolution of the species $B, A, G$ and $M$ in the model given in Table 3 obtained by numerically solving system of ordinary differential equations (Eq.1 with $k_{2}=k_{5}=k_{7}=k_{8}=0$ ) for the intermediates species a) B, b) $M, c$ ) $A$ and d) $G$.

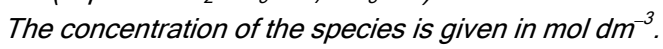

$$
\mathbf{E}=\left[\begin{array}{cc|c}
E_{2} & E_{3} \\
1 & 1 & R_{1} \\
0 & 0 & R_{2} \\
1 & 1 & R_{3} \\
1 & 0 & R_{4} \\
0 & 0 & R_{5} \\
0 & 1 & R_{6} \\
0 & 0 & R_{7} \\
0 & 0 & R_{8} \\
1 & 1
\end{array}\right] R_{9}
$$

The rates at a steady state, $v_{s s}$ are:

$$
\begin{aligned}
& v_{\mathrm{ss}, 1}=j_{2}+j_{3} \\
& v_{\mathrm{ss}, 3}=j_{2}+j_{3} \\
& v_{\mathrm{ss}, 4}=j_{2} \\
& v_{\mathrm{ss}, 6}=j_{3} \\
& v_{\mathrm{ss}, 9}=j_{2}+j_{3}
\end{aligned}
$$

The next step was to examine stability of a steady state by analyzing diagonal minors of matrix $\mathbf{V}(j)$ :

$$
\mathbf{V}(j)=\left[\begin{array}{cccc}
j_{2}+j_{3} & 0 & 0 & 0 \\
0 & 0 & 0 & 0 \\
-\left(j_{2}+j_{3}\right) & 0 & j_{2}+j_{3} & 2 j_{3} \\
0 & 0-\left(j_{2}+j_{3}\right) & j_{2}-j_{3}
\end{array}\right]
$$

This time we found a new instability condition that must be satisfied:

$j_{2}<j_{3}$

resulting in:

$v_{\mathrm{ss}, 4}<v_{\mathrm{ss}, 6}$

The obtained instability condition is in accordance with the one given in expression (24), since in the reduced model the rates of reactions $\left(R_{2}\right)$ and $\left(R_{5}\right)$ are equal to zero.

As we can see from Eq. (27), matrix $\mathbf{V}(j)$ for new model can be reduced to $3 \times 3$ matrix. This is a result of removing reactions $\left(R_{2}\right),\left(R_{5}\right)$ and $\left(R_{7}\right)$ from the model, because the new model has only 3 intermediate species. Therefore, the Hurwitz matrix $\mathbf{H}$ is also a $3 \times 3$ matrix, and now for existence of the Andronow-Hopf bifurcation it is necessary to examine $\Delta_{2}$ :

$\Delta_{2}=\left[\begin{array}{cc}\alpha_{1} & \alpha_{3} \\ 1 & \alpha_{2}\end{array}\right]=\alpha_{1} \alpha_{23}-\alpha_{3}=0$

This allowed us to obtain the full instability condition using the Routh-Hurwitz criterion, which is given in Eq. (24):

$\left(h_{\mathrm{A}}+h_{\mathrm{G}}\right) v_{4}=\left(h_{\mathrm{G}}-h_{\mathrm{A}}\right) v_{6}$

We can see from Eq. (31) that for existence of the Andronow-Hopf bifurcation, it must be satisfied that the concentration of intermediate species $G$ must be 
lower than the concentration of the intermediate species $A$, in the steady state. Although the simplified model is enough to simulate the oscillatory evolution of two intermediate species, the other reactions are obviously necessary to get results that can be correlated with experimentally obtained evolution of HPA system [18].

\section{CONCLUSION}

A systematic approach to the stability analysis of complex chemical reaction networks was applied to a scheme where autocatalytic and autoinhibitory steps are coupled through the same species. The stoichiometric network analysis was used to find positive and negative feedbacks that may cause concentration oscillations of reaction components in the considered model, while sensitivity analysis allowed us to determine the dominant ones.

We have determined that autocatalysis was the dominant process, which was essential for existence of oscillations in the model, while autoinhibition did not play an important role and could be removed from the model without loss of oscillations. This allowed us to simplify the considered model by removing $\left(R_{2}\right),\left(R_{5}\right)$, $\left(R_{7}\right)$ and $\left(R_{8}\right)$, and leave only the important reactions. The simplified model is capable to simulate oscillatory evolution, but only of two intermediate species.

We also determined the full instability condition for the reduced model using the Routh-Hurwitz criterion given by Eq. (31). Based on Eq. (31) we can see that for existence of the oscillations in the model concentration of intermediate species $\mathrm{G}$ must be lower than the concentration of the intermediate species $A$, in the steady state. Therefore, feedback responsible for concentration oscillations of reaction components is result of interaction between intermediate species $A$ and $G$.

\section{Acknowledgement}

The present investigations were partially supported by The Ministry of Education, Science and Technological Development of the Republic of Serbia, under Project 172015 and 45001.

\section{REFERENCES}

[1] Lj. Kolar-Anić, Ž. Čupić, G. Schmitz, S. Anić, Improvement of the stoichiometric network analysis for determination of instability conditions of complex nonlinear reaction systems, Chem. Eng. Sci. 65 (2010) 3718-3728.

[2] S.K. Scott, Reversible Autocatalytic reactions in an isothermal CSTR: Multiplicity, stability and relaxation times, Chem. Eng. Sci. 38 (1983) 1701-1708.

[3] P. Gray, S.K. Scott, Autocatalytic reactions in the isothermal, continuous stirred tank reactor. Isolas and other forms of multistability, Chem. Eng. Sci. 38 (1983) 29-43.
[4] S. Jelić, Ž. Čupić, Lj. Kolar-Anić, Mathematical modeling of the hypothalamic-pituitary-adrenal system activity, Math. Biosci. 197 (2005) 173-187.

[5] B.L. Clarke, Stoichiometric network analysis, Cell Biophys. 12 (1988) 237-253.

[6] S. Jelić, Ž. Čupić, Lj. Kolar-Anić, V. Vukojević, Predictive modeling of the hypothalamic-pituitary-adrenal (HPA) function. Dynamic systems theory approach by stoichiometric network analysis and quenching small Amplitude oscillations, Inter. J. Nonlin. Sci. Num. Sim. 10 (2009) 1451-1472.

[7] B. Clarke, Stability of complex reaction networks, In: I. Prigogine, S. Rice (Eds.), Adv. Chem. Phys., Wiley, New York, 1980, pp. 1-216.

[8] B.L. Clarke, Complete set of steady states for the general stoichiometric dynamical system, J Chem. Phys. 75 (1981) 4970-4979.

[9] B.L. Clarke, Qualitative dynamics and (stability) of chemical reaction networks, in chemical applications of topology and graph theory, R.B. King (Ed.), Elsevier, Amsterdam, 1983, pp. 322-357.

[10] P.E. Lehner, E. Noma, A new solution to the problem of finding all numerical solutions to ordered metric structures, Psychometrika 45 (1980) 135-137.

[11] R. Schuster, S. Schuster, Refined algorithm and computer program for calculating all non-negative fluxes admissible in steady states of biochemical reaction systems with or without some flux rates fixed, Comput. Appl. Biosci. 9 (1993) 79-85.

[12] R. Urbanczik, C. Wagner, An improved algorithm for stoichiometric network analysis: theory and applications, Syst. Biol. 21 (2005) 1203-1210.

[13] J. Gagneur, S. Klamt, Computation of elementary modes: a unifying framework and the new binary approach, BMC Bioinformatics 5 (2004) 175.

[14] Lj. Kolar-Anic, Ž. Čupić, V. Vukojević, S. Anić, Dynamics of Non-linear Processes, Faculty of Physical Chemistry, University of Belgrade, Belgrade, 2011 (in Serbian).

[15] B. L. Clarke,W. Jiang, Method for deriving Hopf and saddle-node bifurcation hypersurfaces and application to a model of the Belousov-Zhabotinskii system, J. Chem. Phys. 99 (1993) 4464-4478.

[16] W. Liu, Criterion of Hopf bifurcation without using eigenvalues, J. Math. Anal. App. 182 (1994) 250-256.

[17] P. Gray, S. K. Scott, A new model for oscillatory behavior in closed systems: The Autocatalator, Ber. Bunsenges, Phys. Chem. 90 (1986) 985-996.

[18] V.M. Marković, Ž. Čupić, V. Vukojević, Lj. Kolar-Anić, Predictive modeling of the hypothalamic-pituitary-adrenal (HPA) axis response to acute and chronic stress, Endocr. J. 58 (2011) 889-904.

[19] J. K. Beers, Numerical methods for chemical engineering - Applications in Matlab, Cambridge University Press, Cambridge, 2007.

[20] C. Grosan, A. Abraham, A new approach for solving nonlinear equations systems, IEEE Trans. Syst. Man Cybern. A Syst. Humans 38 (2008) 698-714. 


\section{APPENDIX I: Sensitivity analysis}

The sensitivity analysis we use in this paper is a continuation method where we change values of parameter of interest $k_{i}$ and determine stability of the system by calculating the Hurwitz determinant necessary for discussion of oscillatory evolution (in the model considered here $\Delta_{3}$ ). Change in value of $k_{i}$ causes change in steady state concentrations of intermediate species. Hence, the first step is to calculate steady state concentrations. The steady state concentrations can be calculated from Eq. (4), which can be written in the form:

$$
\begin{aligned}
& \frac{\mathrm{d} b}{\mathrm{~d} t}=k_{1}-k_{3} b=0 \\
& \frac{\mathrm{d} m}{\mathrm{~d} t}=k_{2}+k_{5} a-k_{7} m g^{2}=0 \\
& \frac{\mathrm{d} a}{\mathrm{~d} t}=k_{3} b-k_{4} a-k_{5} a-k_{6} a g^{2}-k_{8} a=0 \\
& \frac{\mathrm{d} g}{\mathrm{~d} t}=k_{4} a+k_{6} a g^{2}-k_{7} m g^{2}-k_{9} g=0
\end{aligned}
$$

Since the relations between current rates and reaction rates can be obtained from the matrix relation:

$$
v_{\mathrm{sS}}=\mathrm{E} j
$$

one simply finds that:

$$
\begin{aligned}
& v_{\mathrm{ss}, 1}=k_{1}=j_{1}+j_{2}+j_{3}+j_{4}+j_{5}+2 j_{6}+2 j_{7} \\
& v_{\mathrm{ss}, 2}=k_{2}=j_{4}+j_{5} \\
& v_{\mathrm{ss}, 3}=k_{3} b=j_{1}+j_{2}+j_{3}+j_{4}+j_{5}+2 j_{6}+2 j_{7} \\
& v_{\mathrm{ss}, 4}=k_{4} a=j_{2}+j_{4}+j_{6} \\
& v_{\mathrm{ss}, 5}=k_{5} a=j_{6}+j_{7} \\
& v_{\mathrm{ss}, 6}=k_{6} a g^{2}=j_{3}+j_{5}+j_{7} \\
& v_{\mathrm{ss}, 7}=\mathrm{k}_{7} m g^{2}=j_{4}+j_{5}+j_{6}+j_{7} \\
& v_{\mathrm{ss}, 8}=\mathrm{k}_{8} a=j_{1} \\
& v_{\mathrm{ss}, 9}=\mathrm{k}_{9} g=j_{2}+j_{3}
\end{aligned}
$$

Analyzing Eq. (A1.3), we can see that they are correlated by the relations:

$$
\begin{aligned}
& v_{s s, 1}=v_{s s, 3} \\
& v_{s s, 7}=v_{s s, 2}+v_{s s, 5} \\
& v_{s s, 1}=v_{s s, 4}+v_{s s, 5}+v_{s s, 6}+v_{s s, 8} \\
& v_{s s, 3}=v_{s s, 5}+v_{s s, 7}+v_{s s, 8}+v_{s s, 9}
\end{aligned}
$$

From these relations we can find analytical solution for steady state concentrations of intermediate species in the following forms:

$$
\begin{aligned}
& b_{\mathrm{ss}}=\frac{\mathrm{k}_{1}}{\mathrm{k}_{3}} \\
& m_{\mathrm{ss}}=\frac{\mathrm{k}_{2}+\mathrm{k}_{5} a_{\mathrm{ss}}}{\mathrm{k}_{7} g_{\mathrm{ss}}^{2}} \\
& a_{\mathrm{ss}}=\frac{k_{1}}{\left(k_{4}+k_{5}+k_{8}\right)+k_{6} g_{\mathrm{ss}}^{2}}=\frac{k_{1}-k_{2}-k_{9} g_{\mathrm{ss}}}{2 k_{5}+k_{8}} \\
& -k_{6} k_{9} g_{\mathrm{ss}}^{3}+\left(k_{1}-k_{2}\right) k_{6} g_{\mathrm{ss}}^{2}-k_{9}\left(k_{4}+k_{5}+k_{8}\right) g_{\mathrm{ss}}+ \\
& +\left[k_{1}\left(k_{4}-k_{5}\right)-k_{2}\left(k_{4}+k_{5}+k_{8}\right)\right]=0
\end{aligned}
$$

This method of calculating steady state concentrations usually cannot be applied to larger models; therefore, it is necessary to use numerical methods for solving system of nonlinear algebraic equation. A numerical method that is most often used for this purpose is Newton's method, which is described in Appendix II.

Calculated steady state concentrations are then used for calculating the elements of Jacobian matrix $\mathbf{M}$, which is given in Eq. (10). The next step is to calculate the coefficients of characteristic polynomial $\alpha_{i}$ of matrix $\mathbf{M}$. Coefficients $\alpha_{i}$ can be calculated as the sum of all diagonal minors of matrix $\mathbf{M}$ with dimensionality $i$. For example, $\alpha_{1}$ is equal to the sum of diagonal elements, while $\alpha_{2}$ is equal to the sum of all diagonal minors of dimension 2, etc. Calculated coefficients of characteristic polynomial are used for constructing the Hurwitz matrix $\mathbf{H}$, which in the case of the considered model is a $4 \times 4$ matrix given by Eq. (19). From this matrix $\Delta_{3}$ given in Eq. (20), is calculated as a leading principal minor of size $3 \times 3$.

\section{APPENDIX II: Newton's method for solving the system of nonlinear equations}

Newton's method is a root-finding algorithm that uses the first few terms of the Taylor series of a function $f(x)$ in the vicinity of a suspected root. System of nonlinear equations can be given in a form $[19,20]$ :

$$
\begin{gathered}
f_{1}\left(x_{1}, x_{2}, x_{3} \ldots x_{n}\right)=0 \\
f_{2}\left(x_{1}, x_{2}, x_{3} \ldots x_{n}\right)=0 \\
f_{3}\left(x_{1}, x_{2}, x_{3} \ldots x_{n}\right)=0 \\
\vdots \\
f_{n}\left(x_{1}, x_{2}, x_{3} \ldots x_{n}\right)=0
\end{gathered}
$$

For convenience we can think of $\left(x_{1}, x_{2}, x_{3}, \ldots, x_{n}\right)$ as a vector $x$ and $\left(f_{1}, f_{2}, \ldots, f_{n}\right)$ as a vector-valued function $f$. With this notation, we can write the system of Eqs. (A2.1) simply as [19]:

$$
f(x)=0
$$

Using the Taylor expansion and taking only the first derivate, the vector function $f(x)$ can be approximated near $x_{0}$ : 


$$
f(x)=f\left(x_{0}\right)+J\left(x_{0}\right)\left(x-x_{0}\right)
$$

where $J\left(x_{0}\right)$ is Jacobian of the system at $x_{0}$. We wish to find $x$ that makes $f(x)$ equal to the zero vectors, so let us choose $x_{1}$ so that:

$$
f\left(x_{0}\right)+J\left(x_{0}\right)\left(x_{1}-x_{0}\right)=0
$$

Equation (A2.4) can be rewritten as:

$$
J\left(x_{0}\right) \Delta x=-f\left(x_{0}\right)
$$

where $\Delta x$ is $\left(x_{1}-x_{0}\right)$. Since $J\left(x_{0}\right)$ is a known matrix and $-f\left(x_{0}\right)$ is a known vector, this equation is just a system of linear equations $[19,20]$, which can be solved efficiently and accurately. Once we have the solution vector $\Delta \mathrm{x}$, we can obtain our improved estimate $x_{1}$ by:

$$
x_{1}=x_{0}+\Delta x
$$

For subsequent steps, we have the following process:

Solve

$$
J\left(x_{i}\right) \Delta x=-f\left(x_{i}\right)
$$

Let

$$
x_{i+1}=x_{i}+\Delta x
$$

For successful application of Newton's method it is extremely important to have a good initial guess $x_{0}$ [20]. The best way to get a good initial guess is to start from some known solution $x^{*}$ for some value of parameter $k_{i}^{0}$. This solution can be obtained by solving the system of differential equations for $k_{i}^{0}$. Numerical continuation method is then used to follow the solution as $k_{i}$ changes its value.

\section{APPENDIX III: Equations of linearized dynamics}

The stability of the considered steady state is described with the time evolution of small perturbations of $c_{\text {ss }}$ in its vicinity, which will be denoted as $\Delta c$ [14]. The dynamics close to the steady state can be described by the linearized equation:

$$
\frac{\mathrm{d} c}{\mathrm{~d} t}=\frac{\mathrm{d}\left(c_{\mathrm{ss}}+\Delta c\right)}{\mathrm{d} t}=\frac{\mathrm{d} \Delta c}{\mathrm{~d} t}=\mathbf{S} \Delta v \operatorname{diag}(h) \Delta c
$$

where:

$$
\Delta v=v-v_{\mathrm{ss}}
$$

For small perturbations, the expression $\mathbf{S} \Delta v$ necessary for examination of the system evolution in the vicinity of the examined steady state can be linearized by Taylor series taking into account only the first two terms [14]. Let us first do a Taylor expansion for the $i$-th component:

$$
(\mathbf{S} v)_{i}=\sum_{j} \mathbf{s}_{i, j}\left(v_{j, \mathrm{ss}}+\sum_{q}\left(\frac{\partial v_{j}}{\partial c_{q}}\right)_{\mathrm{ss}}\left(c_{q}-c_{q, \mathrm{ss}}\right)+\ldots\right)
$$

By Eq. (4) the first term is equal to zero:

$$
(\mathrm{Sv})_{i}=\sum_{j} \mathrm{~s}_{i, j} v_{j, \mathrm{ss}}=0
$$

Now, let us define the relation:

$\mathbf{K}_{i, j}=\frac{\partial \log v_{j}}{\partial \log c_{i}}=\frac{c_{i}}{v_{j}} \frac{\partial v_{j}}{\partial c_{i}}$

Equation (A3.3) can be transformed into the following one:

$$
(\mathbf{S} v)_{i}=\sum_{j} \mathbf{s}_{i, j} v_{j, \mathrm{ss}}\left(\sum_{q} h_{q} K_{q, j}\left(c_{q}-c_{q, \mathrm{ss}}\right)\right)=\frac{\mathrm{d} \Delta c_{i}}{\mathrm{~d} t}
$$

where $h_{q}$ is reciprocal of the steady state concentrations of the species $q$. For all intermediate species Eq. (A3.6) transforms to:

$$
\begin{aligned}
& \frac{\mathrm{d} \Delta c}{\mathrm{~d} t}=\sum_{i} \sum_{j} \mathbf{s}_{i, j} v_{j, \mathrm{ss}}\left(\sum_{q} h_{q} K_{q, j}\left(c_{q}-c_{q, s \mathrm{~s}}\right)\right)= \\
& =\mathbf{S} \operatorname{diag}(v) \mathbf{K}^{T} \operatorname{diag}(h) \Delta c
\end{aligned}
$$

where Jacobian matrix $\mathbf{M}$ is defined by:

$$
\mathbf{M}=\mathbf{S} \operatorname{diag}(v) \mathbf{K}^{T} \operatorname{diag}(h)
$$

Using Eq. (6), Eq. (A3.8) can be transformed to:

$$
\mathbf{M}=\mathbf{S} \operatorname{diag}(\mathbf{E} j) \mathbf{K}^{T} \operatorname{diag}(h)
$$




\section{IZVOD}

\section{NELINEARNI REAKCIONI SISTEM SA AUTOKATALIZOM I AUTOINHIBICIJOM: STABILNOST DINAMIČKIH STANJA}

Stevan Maćešić ${ }^{1}$, Željko Čupić ${ }^{2}$, Ljiljana Kolar-Anić ${ }^{1}$

${ }^{1}$ Univerzitet u Beogradu, Fakultet za fizičku hemiju, Beograd, Srbija

${ }^{2}$ Univerzitet u Beogradu, Institut za hemiju, tehnologiju i metalurgiju, Centar za katalizu i hemijsko inžinjerstvo, Beograd, Srbija

(Naučni rad)

Većina realnih sistema su nelinearni, zbog čega je ispitivanje nelinearnih sistema od velikog značaja za različite oblasti nauke. Među navedenim sistemima posebno su značajni nelinearni reakcioni sistemi sa povratnom spregom (autokataliza i autoinhibicija) za koje su karakteristične pojave kao što su oscilatorna evolucija ili haos, i koji se mogu sresti u prirodnim, tehnološkim i ekonomskim sistemima. Kako se autokataliza i autoinhibicija često istovremeno mogu naći u realnim sistemima, mi smo analizirali stabilnost jednog reakcionog modela u kome su ova dva procesa spregnuta i pokazali kako stabilnost ovog sistema zavisi od konstanti brzina i koncentracija hemijskih vrsta koje su uključene u model. Nelinearni procesi sa povratnom spregom i odgovarajući modeli uglavnom imaju veliki broj promenljivih zbog čega analiza stabilnosti zahteva upotrebu posebnih matematičkih alata. Za izvođenje analize stabilnosti ispitivanog modela koristili smo unapređeni metod stehiometrijske mrežne analize (SNA) u kombinaciji sa bifurkacionom analizom i analizom osetljivosti. Koristeći navedene metode analize, uspeli smo da izdvojimo reakcije koje predstavljaju jezgro nestabilnosti, i koje su odgovorne za periodičnu evoluciju sistema, na osnovu čega smo uspeli da odredimo uslov koji je neophodan za postojanje Andronov-Hopf bifurkacije.

Ključne reči: Nelinearna dinamika • Stehiometrijska mrežna analiza • Autokataliza • HPA sistem • Bifurkacija Andronov-Hopf 